\title{
Thermal Evolution of Acetic Acid Nanodeposits over 123-180 K on Noncrystalline Ice and Polycrystalline Ice Studied by FTIR Reflection-Absorption Spectroscopy: Hydrogen-bonding Interactions in Acetic Acid and between Acetic Acid and Ice
}

\author{
Q. Gao and K. T. Leung* \\ Department of Chemistry, University of Waterloo, Waterloo, Ontario N2L 3G1, Canada
}

Received: March 29, 2005; In Final Form: May 10, 2005

\begin{abstract}
Acetic acid vapor-deposited on ultrathin noncrystalline ice (NCI) and polycrystalline ice (PCI) films (less than $6 \mathrm{~nm}$ thick) under ultrahigh vacuum conditions has been investigated by using Fourier Transform Infrared Reflection-Absorption Spectroscopy. Pristine acetic acid deposited at $123 \mathrm{~K}$ (on a copper support) appears as an amorphous solid, which undergoes an irreversible phase transformation to a more structurally ordered (polycrystalline) form upon annealing to $153 \mathrm{~K}$. Acetic acid is found to adsorb on NCI and PCI films initially through hydrogen bonding between $\mathrm{C}=\mathrm{O}$ and dangling $\mathrm{OH}$ (of ice), followed by the formation of multilayers at $123 \mathrm{~K}$. Thermal evolution studies of a low exposure of acetic acid on the ultrathin NCI and PCI films show that acetic acid undergoes coevaporation with water likely as an acetic acid hydrate at $155 \mathrm{~K}$, which continues until the entire ice film has been exhausted at $165 \mathrm{~K}$. Above $165 \mathrm{~K}$, the remaining acetic acid solid appears to evaporate without undergoing the phase transformation, in contrast to the case of a high acetic acid exposure. Coevaporation of acetic acid with water is also found to proceed at a faster rate than the subsequent evaporation of acetic acid, which is consistent with the weaker interactions observed in the H-bonded acetic acid hydrate than that in acetic acid solid.
\end{abstract}

\section{Introduction}

Ice has attracted a lot of attention over the past decade due to the relevance of its surface chemistry to heterogeneous processes found in atmospheric sciences, environmental studies, and planetary research. ${ }^{1,2}$ For example, reactions on the surfaces of stratospheric cloud particles play a key role in the formation of the ozone hole over Antarctica. ${ }^{3}$ Heterogeneous processes on aerosol particles could also be responsible for such atmospheric processes as the tropospheric scavenging of ozone in the Arctic ${ }^{4,5}$ and the enhanced midlatitude depletion of ozone. ${ }^{6,7}$ Oxygenated hydrocarbons (including acetaldehyde, acetone, and acetic acid) are particularly important in atmospheric chemistry because they can be easily decomposed to form hydroxyl radicals that are found to be responsible for ozone depletion in the atmosphere. ${ }^{8}$ The study of the uptake or adsorption of oxygenated hydrocarbons in clouds (and in particular on ice particles) and other atmospheric particulates could provide new insights into the heterogeneous chemistry of clouds related to climate change and other environmental issues. ${ }^{9}$

Previous studies have shown that the adsorption of a guest molecule on ice is sensitive to the nature of the guest molecule and the interfacial sites, and the types and extent of the corresponding interactions can be probed by using infrared spectroscopy..$^{10-13}$ These results have been based upon the frequencies observed for the $\mathrm{OH}$ dangling bond of water molecules. ${ }^{13}$ In the solid forms, water is considered to form four hydrogen bonds to other water molecules following the so-called ice rule ${ }^{14}$ but the coordination sites of the water molecules in the case of noncrystalline ice (NCI) may not be fully saturated. Devlin and co-workers have shown that these sites give rise to two IR bands at 3720 and $3696 \mathrm{~cm}^{-1}$, corresponding to doubly

* Address correspondence to this author. E-mail: tong@uwaterloo.ca. coordinated and triply coordinated water molecules, respectively. ${ }^{15,16}$ These $\mathrm{OH}$ dangling-bond features are found to be very weak in comparison to the $\mathrm{OH}$ stretch feature of bulk ice $\left(3800-2800 \mathrm{~cm}^{-1}\right)$ and are sensitive to the types of interactions with other molecules. For example, the study of the adsorption of hydrogen and nitrogen on NCI by Rowland et al. has revealed red shifts of $10 \mathrm{~cm}^{-1}$ in these dangling-bond features for doubly coordinated and triply coordinated adsorption sites..$^{13}$ In the case when strong $\mathrm{H}$-bonding is involved in the adsorption of a guest species, the red shift in the $\mathrm{OH}$ dangling bond is expected to increase. ${ }^{12}$ The weak $\mathrm{OH}$ dangling-bond feature for a guest species (e.g., acetone) upon adsorption on ice could then be obscured by the much stronger $\mathrm{OH}$ stretch feature of the bulk if the magnitude of the red-shift happens to be large. ${ }^{12}$ Moreover, the $\mathrm{CO}$ stretch of carbon monoxide adsorbed on NCI was found to be a doublet at 2153 and $2137 \mathrm{~cm}^{-1}$, corresponding to adsorption at two different types of sites..$^{10}$ The band at 2153 $\mathrm{cm}^{-1}$ is found to locate at a similar position to those of the corresponding $\mathrm{CO}$ stretch for $\mathrm{CO}$ complexes with $\mathrm{HF}, \mathrm{HCl}$, and $\mathrm{HBr}$ at low temperature $(12 \mathrm{~K}),{ }^{17}$ in which $\mathrm{CO}$ acts as a proton acceptor to the $\mathrm{OH}$ dangling bond of the ice substrate. The effects of adsorption of more complicated molecules (polyatomics) have also been studied on ice surfaces. ${ }^{11}$ In particular, Horn et al. observed that the red shifts in the $\mathrm{OH}$ danglingbond features appear to increase with increasing $\mathrm{Cl}$ content in the chlorofluorocarbon series (i.e., $\mathrm{CCl}_{2} \mathrm{~F}_{2}<\mathrm{CCl}_{3} \mathrm{~F}<\mathrm{CCl}_{4}$ ). ${ }^{11}$ The magnitudes of the observed red shifts were further found to show a strong correlation with a number of physicochemical parameters including the molecular polarizability and the $\mathrm{C}-\mathrm{Cl}$ bond dissociation energy. ${ }^{11}$ However, the limited number of compounds surveyed by Horn et al. ${ }^{11}$ did not allow any general conclusions to be made.

Acetic acid $\left(\mathrm{CH}_{3} \mathrm{COOH}\right)$ is one of the simpler organic acids that is commonly used as a benchmark for comparison with 
small inorganic acids (including $\mathrm{HF}$ and $\mathrm{HCl}^{18}$ ) that have been under intense investigation in atmospheric research. As a guest species on ice, acetic acid is fundamentally interesting because the carbonyl and hydroxyl groups can interact with the water molecules on the ice surface through $\mathrm{H}$-bonding interactions with the hydrogen atom in the $\mathrm{OH}$ dangling bond and with the dangling $\mathrm{O}$ atom, respectively. We have previously studied the adsorption of acetone $\left(\mathrm{CH}_{3} \mathrm{COCH}_{3}\right)$ on ice by using FTIR Reflection-Absorption Spectroscopy (FTIR-RAS), ${ }^{19}$ which together with the present study on acetic acid could provide an extended database for contrasting the effects of the hydroxyl groups on the ice surface chemistry. Unlike formic acid $(\mathrm{HCOOH})$, acetic acid is also less likely to form dimers at room temperature and it is therefore easier to handle experimentally.

To date, only a few studies have been reported for the adsorption of acetic acid on ice and no corresponding spectroscopic data are available in the literature. In particular, Hudson et al. have measured the uptake of a series of gaseous organic molecules (acetone, acetaldehyde, acetic acid) on ice below 200 $\mathrm{K},{ }^{20}$ and their results show that acetic acid is bound strongly to the ice surface. Sokolov and Abbatt have also studied the adsorption of $n$-alcohols, acetic acid, and hexanal between 213 and $245 \mathrm{~K}^{21}$ From concentration analyses of ice samples, Guerinot found that acetic acid exists in its molecular form. ${ }^{22}$ In addition, Compoint et al. compared the adsorption geometries and dynamics of acetic acid on/in ice with those of formic acid at $250 \mathrm{~K}$ by classical molecular dynamics simulation, ${ }^{23}$ and they found that acetic acid is bound to the ice surface through the formation of two hydrogen bonds that are influenced only slightly by the steric packing of the methyl group. Furthermore, the calculated free energy profiles show that acetic acid is strongly trapped at the surface of ice at $250 \mathrm{~K}$. Relative to molecular desorption, the penetration of acetic acid into ice at $250 \mathrm{~K}$ should be more favorable, because the corresponding penetration barrier is two or three times smaller than the desorption barrier. ${ }^{23}$ The present work focuses on the interactions of acetic acid with ultrathin NCI and polycrystalline ice (PCI) films by using FTIR-RAS. In addition to the aforementioned interest, acetic acid is also a convenient guest molecule for probing the ice surface chemistry spectroscopically because its chemistry on metal surfaces is well documented ${ }^{24}$ and the gasphase infrared spectrum has been characterized, facilitating easy comparison with the present work.

\section{Experimental Details}

Details of the experimental setup and procedure have been discussed elsewhere. ${ }^{25}$ Briefly, the FTIR-RAS experiments were performed in an ultrahigh-vacuum (UHV) chamber evacuated by a $1701 \mathrm{~s}^{-1}$ turbomolecular pump and a titanium sublimation pump to a base pressure better than $3.0 \times 10^{-9}$ Torr. A vertically mounted, optically flat polycrystalline OFHC copper disk (5.7$\mathrm{cm}$ diameter) directly attached to a liquid nitrogen cooled dewar was used for film growth by vapor deposition. The liquid nitrogen cooled dewar also served as a cryopump reducing the chamber pressure to $5.0 \times 10^{-10}$ Torr during the experiments. The temperature of the sample on the copper disk could be varied by using a resistance heater imbedded in the backside of the copper disk under the control of a temperature controller. The relative temperature measurement was obtained by using two K-type (chromel-alumel) thermocouples mechanically fastened to the front face of the disk to a precision of better than $\pm 2 \mathrm{~K}$, while the uniformity of the temperature across the disk surface was expected to be better than $5 \mathrm{~K}$. To ensure a highly conductive surface with good deposition reproducibility, the copper disk was precleaned before the vapor deposition by sputtering with argon ions at $1.5 \mathrm{keV}$ impact energy at $5.0 \times$ $10^{-6}$ Torr for $30 \mathrm{~min}$.

The infrared beam from a Bruker Equinox 55 FTIR spectrometer (equipped with an air-cooled Globar source) was directed at the condensed sample on the copper disk by a $45^{\circ}$ flat mirror followed by a $90^{\circ}$ refocusing parabolic mirror (with a $40-\mathrm{cm}$ focal length). The IR beam specularly reflected off the sample at $83^{\circ}$ from the surface normal was collected by a second identical parabolic mirror (40-cm focal length) located at the opposite side of the chamber, and finally focused by a smaller parabolic mirror (4.3-cm focal length) onto a liquid nitrogen cooled Mercury Cadmium Telluride detector (energy range: $7000-600 \mathrm{~cm}^{-1}$; sensitivity $\left.>2.5 \times 10^{10} \mathrm{~cm} \mathrm{~Hz}^{1 / 2} \mathrm{~W}^{-1}\right)$. Two differentially pumped $\mathrm{CaF}_{2}$ optical windows are mounted on the UHV chamber to enable the IR beam to pass through and intersect with the sample. The optical path along the mirror optics outside the UHV chamber was enclosed in aluminum boxes and purged with dry nitrogen gas to remove spectral interference due to water vapor and carbon dioxide in the ambient environment.

FTIR-RA spectra of the deposited sample were obtained over the spectral range of $1000-4000 \mathrm{~cm}^{-1}$ by coadding 20 scans at $20 \mathrm{kHz}$ scanner frequency at a preset spectral resolution of 1 $\mathrm{cm}^{-1}$. Background spectra were collected for the bare copper disk at the deposition temperature (before the vapor deposition) by coadding 500 scans at the same resolution setting and were later removed from the spectra collected for the deposited sample. The resulting background-subtracted sample spectra were then presented in the dimensionless absorbance unit, defined as $-\log \left(R / R_{0}\right)$, where $R / R_{0}$ is the ratio of the reflectance of the substrate with and without the adsorbate. The difference of two background-subtracted sample spectra, denoted as difference spectra in the present work, was used to reveal spectral features corresponding to the changes in the deposition process.

Vapors of water (Millipore) and acetic acid (Aldrich, 99.7\% purity) were introduced into the chamber separately through variable precision leak valves after the respective liquid samples have been degassed by several freeze-pump-thaw cycles. Different amounts of acetic acid (in units of Langmuir, $1 \mathrm{~L}=$ $1 \times 10^{-6}$ Torr s) were deposited on an ice film with a preselected film thickness by exposing the film at an appropriate deposition pressure accumulatively for different periods of exposure time. The thickness of the ice film was estimated by using a procedure based on the Fresnel method, which has been given in detail in our previous work. ${ }^{25}$

\section{Results and Discussion}

3.1. Preparation and Characterization of Noncrystalline and Polycrystalline Ice Films. Figure 1a shows the FTIR-RA spectrum of an ice film deposited at $5.0 \times 10^{-7}$ Torr for $900 \mathrm{~s}$ at $123 \mathrm{~K}$, which is estimated to have a film thickness of $\sim 6$ $\mathrm{nm}$ from the Fresnel analysis. ${ }^{25}$ Evidently, the spectrum is dominated by a strong broad band at $3376 \mathrm{~cm}^{-1}$ and a weaker feature at $1656 \mathrm{~cm}^{-1}$, corresponding to the $\mathrm{OH}$ stretching modes and the $\mathrm{HOH}$ bending mode of the bulk, respectively. Furthermore, a sharp but considerably weaker feature at $3696 \mathrm{~cm}^{-1}$ can also be observed, which can be attributed to the $\mathrm{OH}$ dangling-bond mode, i.e., the $\mathrm{OH}$ stretching mode for which the $\mathrm{H}$ atom is not involved in the $\mathrm{H}$-bonding. The spectral assignments are consistent with those made for a thin NCI film. ${ }^{15,16,26}$ The observed spectrum (Figure 1a) also closely resembles the transmission spectrum of a liquid water film at 


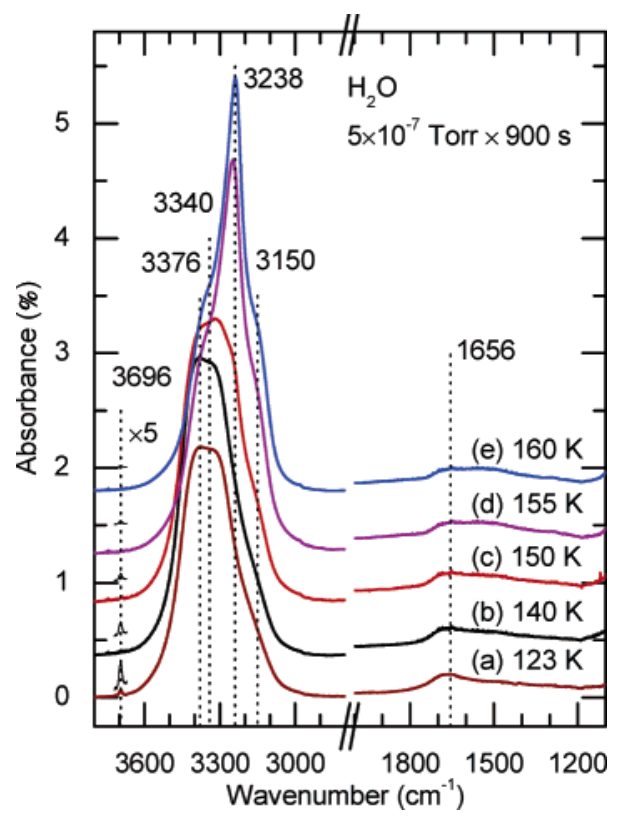

Figure 1. FTIR-RA spectra of (a) an noncrystalline ice film $(\sim 6 \mathrm{~nm}$ thick) vapor-deposited at $5 \times 10^{-7}$ Torr for $900 \mathrm{~s}$ at $123 \mathrm{~K}$, and upon annealing to (b) 140 , (c) 150 , (d) 155 , and (e) $160 \mathrm{~K}$. The conversion to polycrystalline ice film is complete at $160 \mathrm{~K}$.

room temperature (with the exception of the $\mathrm{OH}$ dangling-bond feature at $3696 \mathrm{~cm}^{-1}$ ), which further confirms the amorphous nature of the ice film. ${ }^{27}$

Figure 1 also shows the spectral evolution of the NCI film upon annealing to $160 \mathrm{~K}$. In particular, the bulk $\mathrm{OH}$ stretching feature appears as a sharp peak at $3238 \mathrm{~cm}^{-1}$, while the intensities of the bulk $\mathrm{HOH}$ bending modes (at $1656 \mathrm{~cm}^{-1}$ ) and the $\mathrm{OH}$ dangling-bond mode (at $3696 \mathrm{~cm}^{-1}$ ) are found to decrease (Figure 1e). These spectral changes observed at 160 $\mathrm{K}$ are consistent with those observed for a PCI film. ${ }^{28,29}$ Detailed discussion of the temporal evolution of NCI upon annealing to PCI has been given in our recent work. ${ }^{29}$ As shown in Figure 1, both NCI and PCI films exhibit characteristic spectral features that can be used as fingerprints for easy identification. For the purpose of the present work, we prepared an NCI film by water vapor deposition at $123 \mathrm{~K}$, which was then used to obtain a PCI film by annealing to $160-165 \mathrm{~K}$ for $5 \mathrm{~min}$.

3.2. Characterization of Pristine Acetic Acid Solid Films. Acetic acid can exist in several different forms in the condensed phase. In the liquid phase, acetic acid primarily exists as cyclic dimers, ${ }^{30}$ while evidence for open-chain dimers has also been reported. ${ }^{31}$ In the solid phase, acetic acid has been found to exist as a chainlike polymer. ${ }^{32,33}$ The $\mathrm{C}=\mathrm{O}$ stretching vibration in acetic acid is found to be particularly sensitive to the different physical forms of acetic acid. In particular, while this vibrational mode occurs at 1788 and $1730 \mathrm{~cm}^{-1}$ respectively for the monomer ${ }^{32}$ and dimer in the gas phase, ${ }^{34}$ it is found to shift to $1715 \mathrm{~cm}^{1}$ for the cyclic dimer in the liquid phase. ${ }^{34}$ On the other hand, the $\mathrm{C}=\mathrm{O}$ stretching mode for the chain form in acetic acid solid is usually observed at $1648 \mathrm{~cm}^{-1} .35$

Figure 2 shows the FTIR-RA spectrum of acetic acid deposited at $1.0 \times 10^{-8}$ Torr (deposition pressure) on the copper disk at $123 \mathrm{~K}$ as a function of exposure. The most prominent spectral features have been assigned in accord with the literature data $^{24,32,34-36}$ and are listed in Table 1. In particular, at low exposure (Figure 2a,b), the spectrum shows two prominent features at 1716 and $1304 \mathrm{~cm}^{-1}$, which can be attributed to the $\mathrm{C}=\mathrm{O}$ and $\mathrm{C}-\mathrm{O}$ stretching modes, respectively. These features are found to shift gradually to higher frequencies at higher

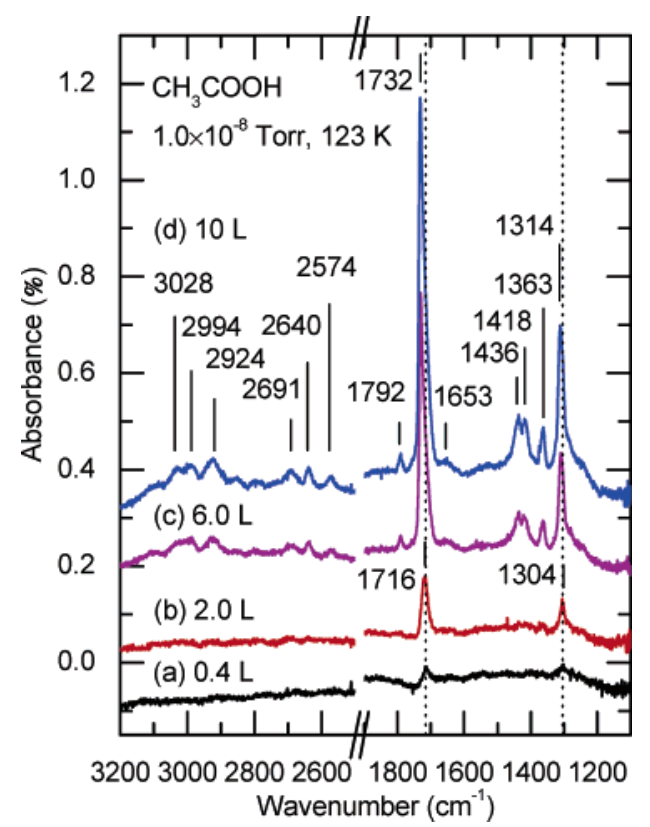

Figure 2. FTIR-RA spectra of acetic acid vapor-deposited at $1.0 \times$ $10^{-8}$ Torr at $123 \mathrm{~K}$ as a function of exposure: (a) 0.4 , (b) 2.0, (c) 6.0, and (d) $10 \mathrm{~L}$.

exposures (Figure 2c,d). Furthermore, additional features at $1653,1436,1418$, and $1363 \mathrm{~cm}^{-1}$ become evident at the $10 \mathrm{~L}$ exposure (Figure $2 \mathrm{~d}$ ), and they can be assigned respectively to the $\mathrm{C}=\mathrm{O}$ stretching mode (of the chain form), $\mathrm{COH}$ scissoring mode, and the $\mathrm{CH}_{3}$ asymmetric and symmetric scissoring modes, in good accord with similar spectral assignments made in the earlier studies for acetic acid solid ${ }^{35}$ and for acetic acid adsorbed on $\mathrm{Pt}(111)^{37}$ and $\mathrm{Ru}(0001){ }^{24}$ The new feature at $1792 \mathrm{~cm}^{-1}$ found at higher exposures (Figure 2d) can also be attributed to the $\mathrm{C}=\mathrm{O}$ stretching mode for acetic acid molecules not participating in the bulk structure, which is similar in frequency to that found for weakly interacting acetic acid monomers (in the gas phase) ${ }^{32}$ Given that the $\mathrm{CO}$ stretching modes (at 1732 and $1314 \mathrm{~cm}^{-1}$ ) for the condensed acetic acid film (for higher exposures) are evidently very similar to those of gas-phase acetic acid dimers $^{34,38}$ (Table 1), the deposition of acetic acid on the copper disk can therefore be characterized as physical adsorption involving the formation of dimers, as previously observed on Pt (111) ${ }^{37}$ and $\mathrm{Ru}(0001){ }^{24}$ At lower exposures, these CO features are found at lower frequencies $\left(1716\right.$ and $\left.1304 \mathrm{~cm}^{-1}\right)$, indicating the differences in the dimer formation in the first (two) adlayers during the initial stage of film growth (on the copper disk). The relative intensities of the present spectrum for the acetic acid film at high exposure (Figure 2d) are also found to be quite different from those for the solid acetic acid spectrum obtained in the transmission mode, ${ }^{35}$ which could be due to the metal surface selection rule and the possible presence of different structures.

Figure 3 shows the thermal evolution of FTIR-RA spectra of $20 \mathrm{~L}$ of acetic acid deposited at $1.0 \times 10^{-8}$ Torr (deposition pressure) at $123 \mathrm{~K}$. These spectra were collected with the sample held at the preselected temperature as indicated in Figure 3. Evidently, three general trends in the changes of the spectral features can be observed upon annealing the sample from 123 to $173 \mathrm{~K}$. In particular, the most prominent feature, $\mathrm{C}=\mathrm{O}$ stretch at $1732 \mathrm{~cm}^{-1}$, observed at $123 \mathrm{~K}$ (Figure 3a and Figure 2d) is found to gradually reduce in intensity. Furthermore, the weak shoulder at $1712 \mathrm{~cm}^{-1}$ (Figure 3b) appears to evolve into a doublet at 1711 and $1720 \mathrm{~cm}^{-1}$ at $153 \mathrm{~K}$ (Figure 3c), which are found to reduce in intensity upon further annealing the 
TABLE 1: Comparison of Vibrational Band Frequencies (in $\mathrm{cm}^{-1}$ ) of Acetic Acid in the Gas Phase, Ar Matrix, Liquid, and Solid Phases, as well as of Acetic Acid Adsorbed on Ru(0001) at $100 \mathrm{~K}$ with Those of Acetic Acid Solids As Deposited at 123 K and upon Annealing to $173 \mathrm{~K}$ Obtained in the Present Work

\begin{tabular}{|c|c|c|c|c|c|c|}
\hline band assignment ${ }^{a}$ & $\begin{array}{c}\text { monomer }^{b} \\
\text { [refs } 32 \text { and 36] }\end{array}$ & $\begin{array}{l}\operatorname{dimer}^{c} \\
\text { [ref 34] }\end{array}$ & $\begin{array}{l}\text { solid phase } \\
\text { [ref 35] }\end{array}$ & $\begin{array}{c}\mathrm{Ru}(0001) \\
{[\mathrm{ref} 24]}\end{array}$ & $\begin{array}{c}\text { solid as deposited } \\
\text { at } 123 \mathrm{~K} \\
\text { [this work] }\end{array}$ & $\begin{array}{c}\text { deposit after being } \\
\text { annealed to } 173 \mathrm{~K} \\
\text { [this work] }\end{array}$ \\
\hline$v(\mathrm{OH})$ & $3583(3566)$ & 3027 (3028) & 2934 & 3028 & 3028 & \\
\hline$v_{\text {as }}\left(\mathrm{CH}_{3}\right)$ & 2996 & 3030 & & 2994 & 2994 & 2995 \\
\hline$v(\mathrm{C}=\mathrm{O})+\delta_{\mathrm{s}}\left(\mathrm{CH}_{3}\right)$ & & & 2988 & & & \\
\hline$v_{\mathrm{s}}\left(\mathrm{CH}_{3}\right)$ & $3051 / 2944$ & 3030 & & 2924 & 2924 & 2931 \\
\hline$\delta(\mathrm{COH})+v_{\mathrm{s}}\left(\mathrm{CH}_{3}\right)$ & & & 2760 & & & \\
\hline$v(\mathrm{C}-\mathrm{O})+\delta(\mathrm{OH})$ & & & 2664 & 2691 & 2691 & 2674 \\
\hline$v(\mathrm{C}-\mathrm{O})+\delta_{\mathrm{s}}\left(\mathrm{CH}_{3}\right)$ & & & 2614 & 2641 & 2640 & 2621 \\
\hline $2 v(\mathrm{C}-\mathrm{O})$ & & & 2519 & 2575 & 2574 & 2576 \\
\hline \multirow{3}{*}{$v(\mathrm{C}=\mathrm{O})$} & $1788(1779)$ & $1730(1715)$ & 1715 & 1794 & 1792 & $1790 / 1749$ \\
\hline & & & 1659 & 1732 & 1732 & 1700 \\
\hline & & & & & 1653 & $1660 / 1646$ \\
\hline$\delta(\mathrm{OCO})+v(\mathrm{CC})$ & & & 1520 & & & 1529 \\
\hline$\delta(\mathrm{COH})$ & $1182(1181)$ & $1422(1413)$ & 1406 & 1439 & 1436 & 1447 \\
\hline$\delta_{\mathrm{as}}\left(\mathrm{CH}_{3}\right)$ & 1430 (1439) & $1422(1413)$ & & 1418 & 1418 & $1423 / 1412$ \\
\hline$\delta_{\mathrm{s}}\left(\mathrm{CH}_{3}\right)$ & $1382(1380)$ & 1365 (1359) & 1365 & 1366 & 1363 & $1370 / 1365$ \\
\hline$v(\mathrm{C}-\mathrm{O})$ & 1264 (1259) & $1292(1295)$ & 1269 & 1313 & 1314 & $\begin{array}{l}1323 / 1301 \\
1284\end{array}$ \\
\hline$\rho_{\text {as }}\left(\mathrm{CH}_{3}\right)$ & $1048(1044)$ & $1060(1050)$ & 1049 & 1053 & & \\
\hline$\rho_{\mathrm{s}}\left(\mathrm{CH}_{3}\right)$ & $989(987)$ & 1005 (1013) & 1018 & 1024 & & \\
\hline$\gamma(\mathrm{OH})$ & & $940(934)$ & 906 & 959 & & \\
\hline$v(\mathrm{C}-\mathrm{C})$ & 847 & $890(886)$ & 891 & & & \\
\hline$\delta(\mathrm{OCO})$ & $642(639)$ & $621(624)$ & 629 & & & \\
\hline$\rho(\mathrm{OCO})$ & $581(581)$ & & 473 & & & \\
\hline$\delta(\mathrm{CCO})$ & & $475(480)$ & 449 & & & \\
\hline
\end{tabular}

${ }^{a}$ Band notations: $v=$ stretch, $\delta=$ scissor, $\rho=$ rock, $\gamma=$ twist, $\mathrm{s}=$ symmetric, as $=$ asymmetric. ${ }^{b}$ Data for the gas-phase monomers are compared with those obtained in an Ar matrix shown in parentheses. ${ }^{c}$ Data for the gas-phase dimers are compared with those obtained in the liquid phase shown in parentheses.

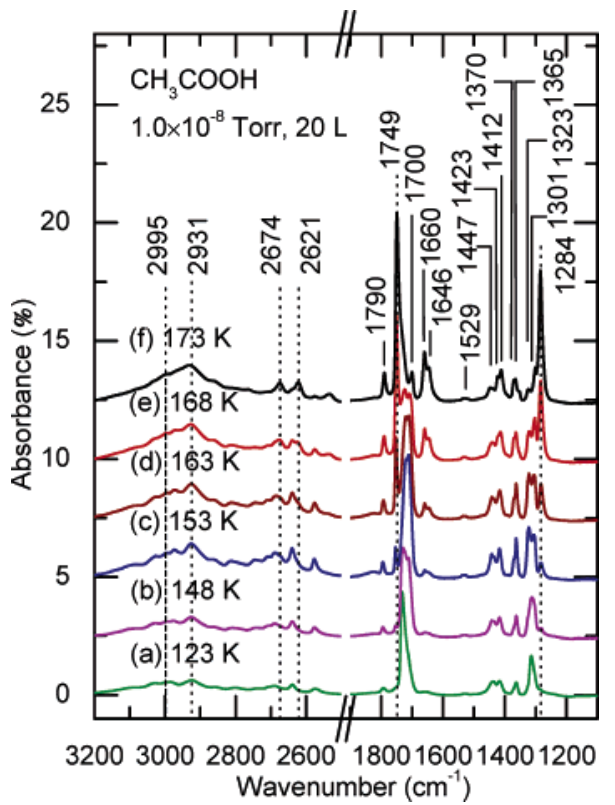

Figure 3. FTIR-RA spectra of $20 \mathrm{~L}$ of acetic acid vapor-deposited at $1.0 \times 10^{-8}$ Torr (a) at $123 \mathrm{~K}$, and upon annealing to (b) 148 , (c) 153 , (d) 163 , (e) 168 , and (f) $173 \mathrm{~K}$.

sample to $173 \mathrm{~K}$ (Figure $3 \mathrm{f}$ ). On the other hand, new $\mathrm{C}=\mathrm{O}$ stretch features at 1660 and $1646 \mathrm{~cm}^{-1}$ are found to increase in intensity during the thermal evolution from 123 to $173 \mathrm{~K}$. Given that the original prominent $\mathrm{C}=\mathrm{O}$ stretch feature at $1732 \mathrm{~cm}^{-1}$ can be attributed to that of the acetic acid dimers in the noncrystalline solid phase ${ }^{34}$ while those at 1660 and $1646 \mathrm{~cm}^{-1}$ could be assigned to bulk polymer in the solid, ${ }^{35}$ the intermediate features at 1711 and $1720 \mathrm{~cm}^{-1}$ could therefore be attributed to intermediate (oligomer) structures between the dimer and chain-form polymer structures. The peaking of the intensity of the doublets of the intermediate structures upon thermal annealing suggests a phase transition of acetic acid from a noncrystalline state to a crystalline state. Furthermore, the weak feature at $1792 \mathrm{~cm}^{-1}$ (Figure 3a and Figure 2d) and the new feature at $1749 \mathrm{~cm}^{-1}$ (Figure 3f) can be attributed to the $\mathrm{C}=\mathrm{O}$ stretch of acetic acid monomers located on the surface (surface monomers) and of those trapped in the bulk (bulk monomers), respectively, not directly interacting with the bulk structure. The strengthening of both of these monomer $\mathrm{C}=\mathrm{O}$ stretch features upon annealing the sample to $173 \mathrm{~K}$ (Figure $3 \mathrm{f}$ ) is consistent with the crystallization process.

Similar thermal evolution in the $\mathrm{C}-\mathrm{O}$ stretch region can also be observed. In particular, the strong $\mathrm{C}-\mathrm{O}$ stretch feature at $1314 \mathrm{~cm}^{-1}$ at $123 \mathrm{~K}$ (Figure 3a and Figure 2d) is found to evolve into a doublet at 1322 and $1306 \mathrm{~cm}^{-1}$ with slightly enhanced intensity at $153 \mathrm{~K}$ (Figure 3c), which then undergoes reduction in intensity upon further annealing the sample to $173 \mathrm{~K}$ (Figure 3f). These spectral changes are consistent with thermal evolution of the bulk dimer to chain-form polymer, as proposed above. The rapid increase in the intensity of the new feature at 1284 $\mathrm{cm}^{-1}$ in concert with the new $\mathrm{C}=\mathrm{O}$ stretch feature at $1749 \mathrm{~cm}^{-1}$ with increasing temperature (observed above) can therefore be used to assign the feature at $1284 \mathrm{~cm}^{-1}$ similarly to the $\mathrm{C}-\mathrm{O}$ stretch of the bulk monomers. The presence of the $\mathrm{C}-\mathrm{O}$ stretch feature for the surface monomers expected to be above 1284 $\mathrm{cm}^{-1}$ could be hidden by the nearby strong dimer/polymer features, which could contribute to the more complex profile changes found in the $\mathrm{C}-\mathrm{O}$ stretch region at different annealing temperatures (Figure 3f).

Crystallization from noncrystalline to crystalline acetic acid solid is also evident in the thermal evolution of the symmetric and asymmetric bending modes of the $\mathrm{CH}_{3}$ group found at 1363 and $1418 \mathrm{~cm}^{-1}$ respectively, as well as the $\mathrm{COH}$ bending mode observed at $1436 \mathrm{~cm}^{-1}$ at $123 \mathrm{~K}$ (Figure 3a and Figure 2d). 


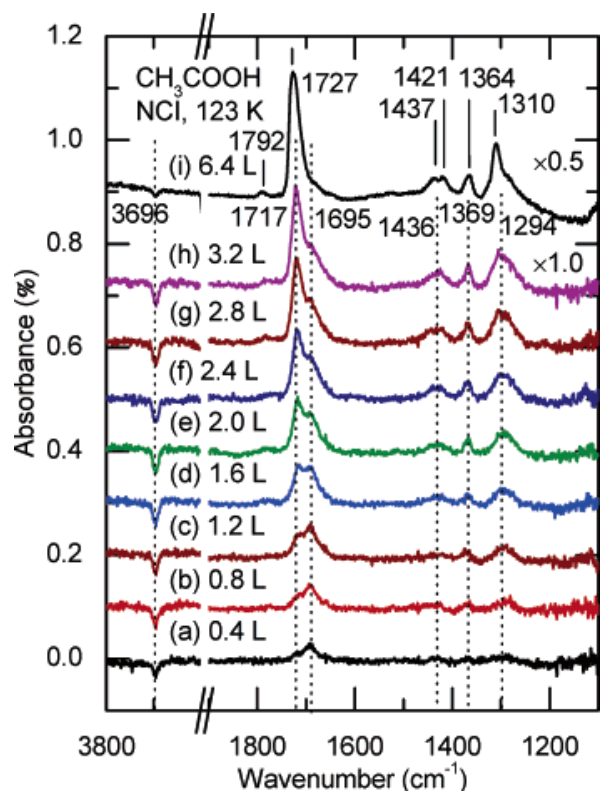

Figure 4. FTIR-RA difference spectra of acetic acid vapor-deposited at $2.0 \times 10^{-9}$ Torr on a noncrystalline ice (NCI) film at $123 \mathrm{~K}$ as a function of acetic acid exposure: (a) 0.4, (b) 0.8, (c) 1.2, (d) 1.6, (e) 2.0, (f) 2.4, (g) 2.8, (h) 3.2 , and (i) $6.4 \mathrm{~L}$.

Like the $\mathrm{C}=\mathrm{O}$ stretching mode for the intermediate oligomer forms at $1712 \mathrm{~cm}^{-1}$, these features appear to increase in intensity upon annealing the sample to $153 \mathrm{~K}$ (Figure 3c) and then weaken upon further annealing to $173 \mathrm{~K}$ (Figure $3 \mathrm{f}$ ). These changes are less pronounced than those found for the $\mathrm{CO}$ stretching modes because these functional groups are not directly involved in intermolecular bonding. Furthermore, the spectral changes in the $2500-2800 \mathrm{~cm}^{-1}$ region corresponding to various combination bands and those above $2800 \mathrm{~cm}^{-1}$ corresponding to the $\mathrm{CH}_{3}$ stretching modes (at 2924 and $2994 \mathrm{~cm}^{-1}$ ) and $\mathrm{OH}$ stretching mode (at $3028 \mathrm{~cm}^{-1}$ ) (Figure 2d, Table 1) are more difficult to characterize over the annealing temperature range due to the multitude, broadness, and complexities of many of these features. In particular, the combination band in the 2500$2800 \mathrm{~cm}^{-1}$ region appears to reach a maximum near $153 \mathrm{~K}$ (Figure 3c), which is consistent with the spectral behavior in the aforementioned crystallization process for some of the constituent functional groups (CO) that are directly involved in the intermolecular bonding. Above $2800 \mathrm{~cm}^{-1}$, the broad spectrum generally increases in intensity upon annealing the sample to $173 \mathrm{~K}$ (Figure 3f). Finally, it is important to note that the crystallization process of acetic acid is irreversible, i.e., the spectrum collected with the acetic acid film held at $173 \mathrm{~K}$ (Figure 3f) remains unchanged after the film was re-cooled back to $123 \mathrm{~K}$. This crystallization process is therefore similar to that found for transformation from NCI to PCI as demonstrated in our recent work. ${ }^{29}$

3.3. Adsorption of Acetic Acid on Noncrystalline and Polycrystalline Ice Films. Figures 4 and 5 shows the FTIRRA difference spectra of acetic acid vapor-deposited at $2.0 \times$ $10^{-9}$ Torr (deposition pressure) as a function of exposure on $\mathrm{NCI}$ and PCI films (approximately $6 \mathrm{~nm}$ thick), respectively. The difference spectra were obtained by subtracting the FTIRRA spectra of the corresponding pristine NCI or PCI film from the sample spectra. It should be noted that the choice of the ice film thickness was arbitrary but the present thickness (i.e., 6 $\mathrm{nm}$ ) appears to be large enough to provide a sufficient proportion of $\mathrm{OH}$ dangling bonds for the present investigation. At submonolayer exposure (Figure $4 \mathrm{a}$ ), the $\mathrm{C}=\mathrm{O}$ stretching mode

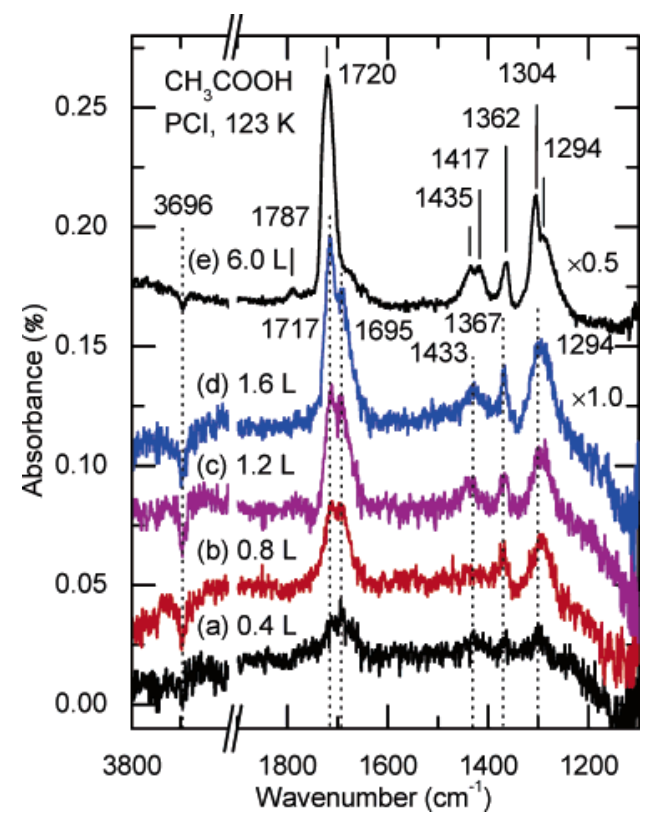

Figure 5. FTIR-RA difference spectra of acetic acid vapor-deposited at $2.0 \times 10^{-9}$ Torr on a polycrystalline ice (PCI) film at $123 \mathrm{~K}$ as a function of acetic acid exposure: (a) 0.4, (b) 0.8, (c) 1.2, (d) 1.6, and (e) $6.0 \mathrm{~L}$

evidently emerges as a weak profile consisting of two components at 1717 and $1695 \mathrm{~cm}^{-1}$. As the exposure is increased, the relative intensity of the component feature at $1717 \mathrm{~cm}^{-1}$ is found to overtake that of the feature at $1695 \mathrm{~cm}^{-1}$, with the latter saturating at $1.2 \mathrm{~L}$ exposure (Figure $4 \mathrm{c}$ ). Concomitantly, the intensity of the $\mathrm{OH}$ dangling-bond feature at $3696 \mathrm{~cm}^{-1}$ is found to decrease with increasing exposure (Figure $4 \mathrm{a}-\mathrm{c}$ ). Above 1.2 $\mathrm{L}$, no further increase in the intensity of the $\mathrm{C}=\mathrm{O}$ stretch feature at $1695 \mathrm{~cm}^{-1}$ nor decrease in that of the $\mathrm{OH}$ dangling-bond feature at $3696 \mathrm{~cm}^{-1}$ with increasing exposure are observed (Figure $4 \mathrm{~d}-\mathrm{h}$ ). The strong inverse correlation in intensity between the $\mathrm{C}=\mathrm{O}$ stretch feature at $1695 \mathrm{~cm}^{-1}$ and the $\mathrm{OH}$ dangling-bond feature at $3696 \mathrm{~cm}^{-1}$ at low exposure strongly suggests that the $\mathrm{C}=\mathrm{O}$ stretch feature at $1695 \mathrm{~cm}^{-1}$ corresponds to the formation of a surface complex of acetic acid (monolayer) with the dangling bonds of the ice film. On the other hand, the $\mathrm{C}=\mathrm{O}$ stretch feature at $1717 \mathrm{~cm}^{-1}$ is found to strengthen further with increasing exposure, suggesting that this feature could be attributed to acetic acid in multilayers. In addition, the $\mathrm{C}-\mathrm{O}$ stretch feature at $1294 \mathrm{~cm}^{-1}$, and the symmetric and asymmetric $\mathrm{CH}_{3}$ bending modes at 1369 and $1436 \mathrm{~cm}^{-1}$, respectively, are found to increase in intensity with increasing exposure (Figure 4). Unlike the $\mathrm{C}=\mathrm{O}$ stretching feature at $1695 \mathrm{~cm}^{-1}$, saturation of these features related to monolayer bonding is not observed, which suggests that the $\mathrm{OH}$ dangling bond of the ice surface does not strongly interact with the $\mathrm{C}-\mathrm{O}$ and $\mathrm{CH}_{3}$ constituent groups.

The FTIR-RA difference spectra for acetic acid on PCI (Figure 5) are found to exhibit similar vibrational features for acetic acid with similar frequencies as those found on NCI (Figure 4). These spectra also follow a similar trend with increasing exposure as that found for acetic acid on NCI (Figure 4). In particular, the increase in the $\mathrm{C}=\mathrm{O}$ stretching mode at $1695 \mathrm{~cm}^{-1}$ is also found to correlate with a concomitant reduction in the $\mathrm{OH}$ dangling-bond signal at $3696 \mathrm{~cm}^{-1}$ for submonolayer exposures (Figure $5 \mathrm{a}-\mathrm{d}$ ), again supporting our hypothesis that the $\mathrm{C}=\mathrm{O}$ stretch feature at $1695 \mathrm{~cm}^{-1}$ corresponds to interactions of acetic acid in the first monolayer with the ice surface. The lack of saturation of the other $\mathrm{C}=\mathrm{O}$ stretch 


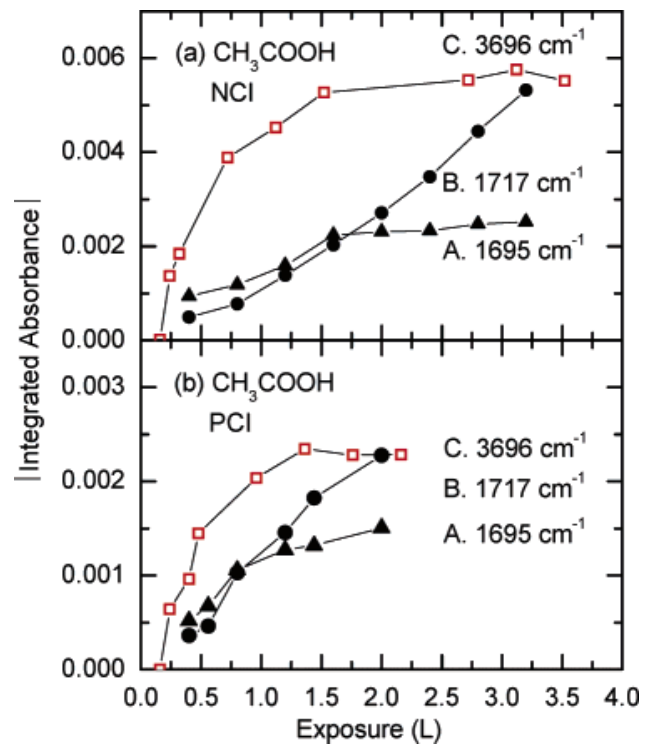

Figure 6. Profiles of the magnitudes of integrated absorbance of FTIRRA difference spectral features at (A) 1695 (A), (B) 1717 (๑), and (C) $3696 \mathrm{~cm}^{-1}(\square)$ of acetic acid deposited at $2.0 \times 10^{-9}$ Torr as a function of acetic acid exposure on (a) noncrystalline ice (NCI) and (b) polycrystalline ice (PCI) at $123 \mathrm{~K}$.

feature at $1717 \mathrm{~cm}^{-1}$ can therefore be attributed to acetic acid in multilayer adsorption. Moreover, the $\mathrm{C}-\mathrm{O}$ stretch at 1294 $\mathrm{cm}^{-1}$ and the symmetric and asymmetric bending modes of $\mathrm{CH}_{3}$ at 1433 and $1367 \mathrm{~cm}^{-1}$, respectively, are also found to increase in intensity with increasing exposure (Figure $5 \mathrm{a}-\mathrm{d}$ ), which also indicates weak interactions between these constituent groups with ice.

Further exposure of acetic acid to PCI (Figure 5e) and to NCI (Figure $4 \mathrm{i}$ ) at $123 \mathrm{~K}$ to $\sim 6 \mathrm{~L}$ produces difference spectra similar to that of acetic acid solid film (Figure 2c), which shows that the effect of the substrate is no longer important for the thicker acetic acid film. At higher exposure, the small but discernible blue shift of the $\mathrm{C}=\mathrm{O}$ stretch from $1717 \mathrm{~cm}^{-1}$ for $1.6 \mathrm{~L}$ (Figure $5 \mathrm{~d}$ ) to $1720 \mathrm{~cm}^{-1}$ for $6.0 \mathrm{~L}$ exposure (Figure $5 \mathrm{e}$ ) is found to be consistent with the continued build up of the multilayer with increasing exposure on PCI, as observed similarly for acetic acid solid film (Figure 2) and for acetic acid on NCI [e.g., from $1717 \mathrm{~cm}^{-1}$ for $3.2 \mathrm{~L}$ (Figure 4h) to 1727 $\mathrm{cm}^{-1}$ for $6.4 \mathrm{~L}$ (Figure $4 \mathrm{i}$ )].

We have estimated the spectral intensities of the two $\mathrm{C}=\mathrm{O}$ features and the $\mathrm{OH}$ dangling-bond features by a nonlinear leastsquares fitting procedure involving primarily Gaussian mixed with Lorentzian line shapes, and the corresponding integrated absorbance profiles as a function of acetic acid exposure on NCI and PCI are shown in Figure 6. These profiles show that the adsorption of acetic acid on NCI and PCI follows a similar pattern, in which the acetic acid molecule binds to the ice surface through interactions between $\mathrm{C}=\mathrm{O}$ and the $\mathrm{OH}$ dangling bond during the early stage of adsorption (i.e. before complete adsorption of a monolayer). The increase in the intensity of the monolayer $\mathrm{C}=\mathrm{O}$ stretch feature at $1695 \mathrm{~cm}^{-1}$ (Figure 6, curves A) appears to level off near $1.2 \mathrm{~L}$, while that for the multilayer $\mathrm{C}=\mathrm{O}$ stretch feature at $1717 \mathrm{~cm}^{-1}$ (Figure 6, curves B) continues to increase with increasing exposure. The lower magnitude of the depleted dangling-bond signal for saturation adsorption on PCI than that on NCI is consistent with the relative number of $\mathrm{OH}$ dangling bonds on the PCI and NCI films. Furthermore, the slightly lower saturation exposure of acetic acid for PCI $(0.7 \mathrm{~L})$ relative to that for NCI $(0.9 \mathrm{~L})$ indicates a lower proportion of acetic acid per dangling-bond interaction for PCI

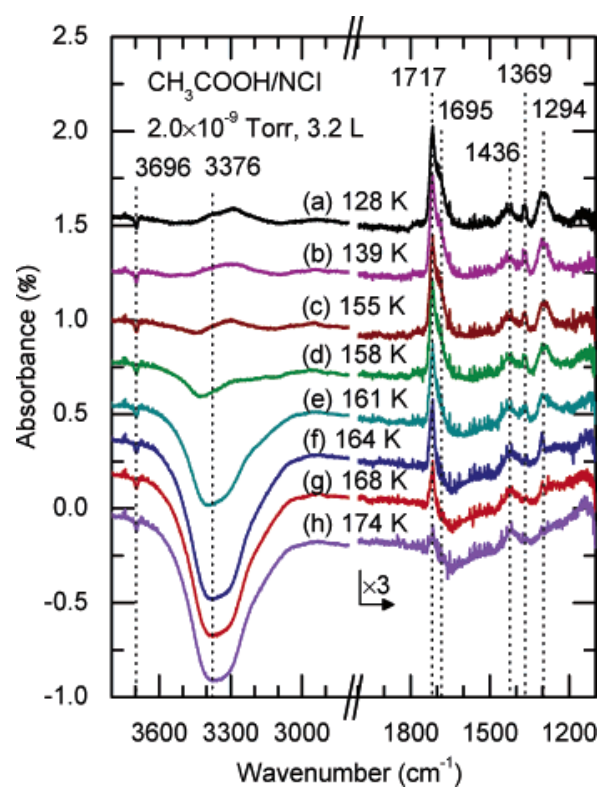

Figure 7. FTIR-RA difference spectra of $3.2 \mathrm{~L}$ of acetic acid vapordeposited at $2.0 \times 10^{-9}$ Torr on a noncrystalline ice (NCI) film at 123 $\mathrm{K}$ as a function of annealing temperature: (a) 128, (b) 139, (c) 155, (d) 158 , (e) 161, (f) 164, (g) 168, and (h) $174 \mathrm{~K}$.

than NCI, suggesting that there are fewer dangling-bond sites available for bonding with acetic acid on PCI than NCI. (The saturation exposures were estimated from the respective curves in Figure 6 by the intercepts of two straight lines drawn from the 3-4 points at the low and high exposure sides.) It should be noted that examination of the ice spectral region before and after the adsorption of acetic acid shows complete extinction of the dangling-bond signal upon complete adsorption of the first monolayer. Furthermore, the presence of the $\mathrm{C}=\mathrm{O}$ stretching mode corresponding to multilayer adsorption is discernible even at the lowest exposure employed in the present work, which would suggest that island formation has already occurred before the completion of the first monolayer adsorption of acetic acid.

3.4. Thermal Evolution of Acetic Acid on Noncrystalline and Polycrystalline Ice Films. Figures 7 and 8 show the thermal evolution of the FTIR-RA difference spectra of 3.2 and $1.8 \mathrm{~L}$ of acetic acid vapor-deposited at $2.0 \times 10^{-9}$ Torr (deposition pressure) respectively on NCI and PCI films (approximately $6 \mathrm{~nm}$ thick). The difference spectra were obtained by subtracting the FTIR-RA spectra of the corresponding pristine NCI (Figure 1a) or PCI film (Figure 1e) obtained at $123 \mathrm{~K}$ from the sample spectra collected at a preselected sample temperature (indicated in Figures 7 and 8). Evidently, the intensity of the monolayer $\mathrm{C}=\mathrm{O}$ stretch feature at $1695 \mathrm{~cm}^{-1}$ appears to decrease with increasing temperature and become totally diminished at $164 \mathrm{~K}$ (Figure $7 \mathrm{f}$ ), while the intensity of the more prominent multilayer $\mathrm{C}=\mathrm{O}$ stretch feature at 1717 $\mathrm{cm}^{-1}$ remains essentially unchanged from 128 (Figure 7a) to $164 \mathrm{~K}$ (Figure 7f). This multilayer $\mathrm{C}=\mathrm{O}$ stretch feature weakens with increasing temperature only after the extinction of the monolayer $\mathrm{C}=\mathrm{O}$ stretch feature above $164 \mathrm{~K}$. Furthermore, thermal evolution of the $\mathrm{COH}$ bending feature at $1436 \mathrm{~cm}^{-1}$, the $\mathrm{CH}_{3}$ bending features at $1369 \mathrm{~cm}^{-1}$, and the $\mathrm{C}-\mathrm{O}$ stretch feature at $1294 \mathrm{~cm}^{-1}$ follow that of the multilayer $\mathrm{C}=\mathrm{O}$ stretch, confirming that these vibrational modes contain predominant contributions from the multilayer component of the acetic acid film. However, the $\mathrm{C}-\mathrm{O}$ stretch feature at $1294 \mathrm{~cm}^{-1}$ becomes markedly sharpened at $164 \mathrm{~K}$, which suggests that the depleted component located at the lower frequency near $1284 \mathrm{~cm}^{-1}$ is related to the monolayer component and therefore should follow 


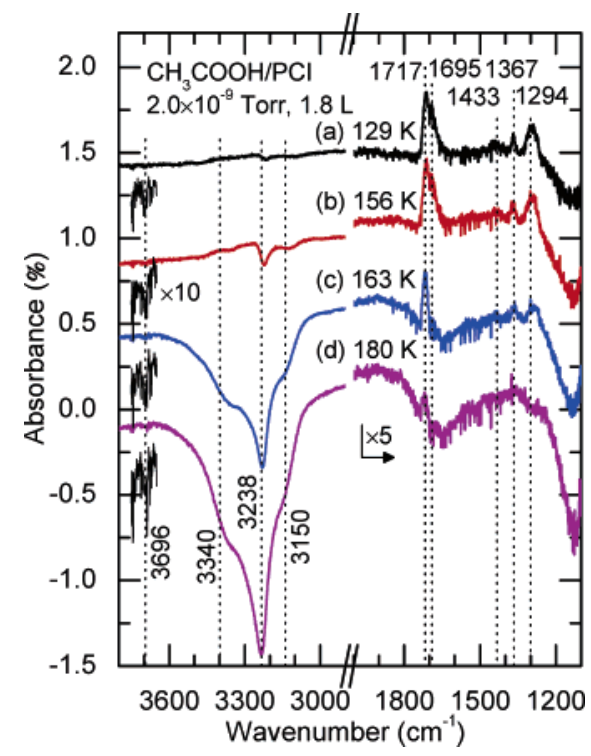

Figure 8. FTIR-RA difference spectra of $1.8 \mathrm{~L}$ of acetic acid vapordeposited at $2.0 \times 10^{-9}$ Torr on a polycrystalline ice (PCI) film at 123 $\mathrm{K}$ as a function of annealing temperature: (a) 129, (b) 156 , (c) 163 , and (d) $180 \mathrm{~K}$.

similar thermal evolution as that of the $\mathrm{C}=\mathrm{O}$ stretch feature at $1695 \mathrm{~cm}^{-1}$. In addition, minor reduction in the intensity and minor change in the shape of the $\mathrm{OH}$ stretch feature near 3376 $\mathrm{cm}^{-1}$ are found upon annealing the sample from 128 (Figure 7a) to $158 \mathrm{~K}$ (Figure $7 \mathrm{~d}$ ). However, we did not observe the shape normally expected for a PCI film near $160 \mathrm{~K}$ (Figure 1e), which indicates that the transformation from NCI to PCI (Figure 1) has not occurred. Moreover, further annealing the sample to $164 \mathrm{~K}$ caused major depletion in the intensity of the $\mathrm{OH}$ stretch of the NCI film (Figure 7f), which appears to correlate well with the complete depletion of the first-monolayer $\mathrm{C}=\mathrm{O}$ stretch feature at $1695 \mathrm{~cm}^{-1}$. The presence of acetic acid with strong $\mathrm{H}$-bonding interaction on the ice surface therefore appears to not only prevent crystallization of the NCI film, but also induce coevaporation of acetic acid with water. Annealing the sample (from $164 \mathrm{~K}$ ) further to $174 \mathrm{~K}$ appears to cause reduction in the remaining acetic acid, after complete evaporation of the NCI film. Furthermore, the $\mathrm{OH}$ dangling-bond feature at $3696 \mathrm{~cm}^{-1}$ has been completely quenched upon exposure of acetic acid above 1.2 L, as illustrated in Figure 4. No significant change in this feature is found upon thermal annealing from 128 to $174 \mathrm{~K}$ (Figure 7), which further supports the strong $\mathrm{H}$-bonding interaction between acetic acid and water in the interface (first-monolayer) region.

The thermal evolution of $1.8 \mathrm{~L}$ of acetic acid on the PCI film (Figure 8) follows a similar trend as that of $3.2 \mathrm{~L}$ of acetic acid on the NCI film (Figure 7). In particular, the reduction in the intensity of the monolayer $\mathrm{C}=\mathrm{O}$ stretch feature at $1695 \mathrm{~cm}^{-1}$ from $129 \mathrm{~K}$ (Figure 8a) to $163 \mathrm{~K}$ (Figure 8c) is followed by reduction in that of the multilayer $\mathrm{C}=\mathrm{O}$ stretch feature at 1717 $\mathrm{cm}^{-1}$ at a higher temperature $(180 \mathrm{~K}$, Figure $8 \mathrm{~d})$. The changes in the intensity of the multilayer $\mathrm{C}=\mathrm{O}$ stretch with increasing temperature are similar to those of the $\mathrm{COH}$ bending feature at $1433 \mathrm{~cm}^{-1}$, the $\mathrm{CH}_{3}$ bending features at $1367 \mathrm{~cm}^{-1}$, and the $\mathrm{C}-\mathrm{O}$ stretch feature at $1294 \mathrm{~cm}^{-1}$. The immediate quenching of the dangling-bond feature at $3696 \mathrm{~cm}^{-1}$ upon adsorption of acetic acid supports the strong $\mathrm{H}$-bonding interaction between acetic acid and water observed also for the NCI film. The PCI film clearly exhibits the characteristic $\mathrm{OH}$ stretch profile, with the maximum at $3238 \mathrm{~cm}^{-1}$ (Figure 8). The gradual depletion

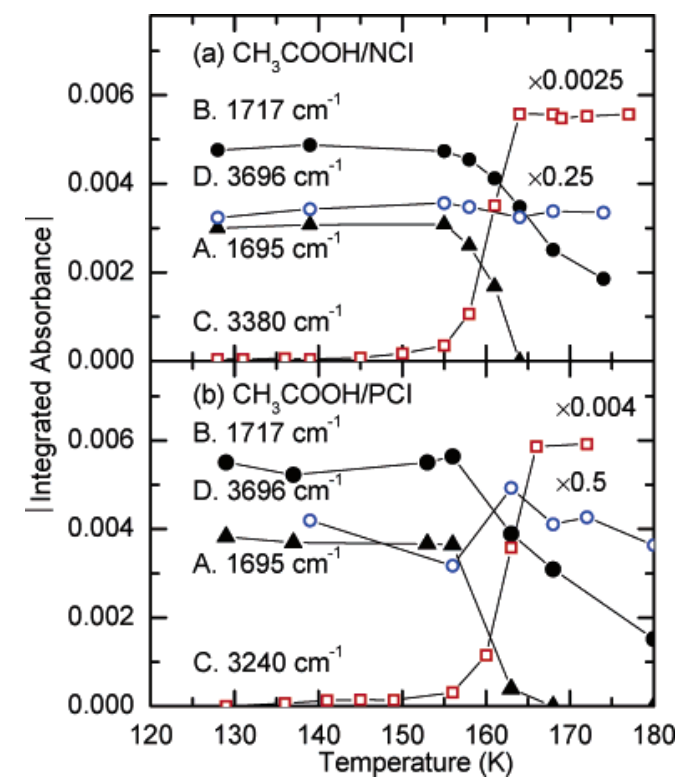

Figure 9. Profiles of the magnitudes of integrated absorbance of FTIRRA difference spectral features at (A) 1695 (ム), (B) 1717 (C), (C) $3380 / 3240(\square)$, and (D) $3696 \mathrm{~cm}^{-1}$ (O) of 3.2 and $1.8 \mathrm{~L}$ of acetic acid vapor-deposited at $2.0 \times 10^{-9}$ Torr as a function of annealing temperature on respectively (a) noncrystalline ice (NCI) and (b) polycrystalline ice $(\mathrm{PCI})$ at $123 \mathrm{~K}$.

of the intensity of this feature with increasing temperature to $163 \mathrm{~K}$ (Figure 8c), in concert with the reduction in that of the monolayer $\mathrm{C}=\mathrm{O}$ stretch feature at $1695 \mathrm{~cm}^{-1}$, again indicates water coevaporating with acetic acid (likely as an acetic acid hydrate). This coevaporation continues until the complete PCI film has been exhausted, after which evaporation of the remaining acetic acid solid film continues to proceed with increasing temperature. As with the adsorption of a low exposure of acetic acid on the NCI film, the acetic acid adsorbed on the PCI film does not appear to exhibit crystallization upon annealing above $153 \mathrm{~K}$ (the on-set of crystallization observed in Figure 3). The lack of transformation to a crystalline state is likely due to the relatively small amount of acetic acid adsorbed on the NCI and PCI films.

Our proposed picture for the thermal evolution of acetic acid on NCI and PCI films can be summarized by the integrated absorbance profiles of the monolayer and multilayer $\mathrm{C}=\mathrm{O}$ stretching modes, $\mathrm{OH}$ stretching, and $\mathrm{OH}$ dangling-bond features as a function of temperature, shown in Figure 9. Integrated absorbance is estimated by integrating the absolute magnitude of the absorbance over the vibrational feature of interest in the respective difference spectra (Figures 7 and 8). The monolayer and multilayer $\mathrm{C}=\mathrm{O}$ features at 1695 and $1717 \mathrm{~cm}^{-1}$, respectively, have been fitted with Gaussian-Lorentzian line shapes in order to determine the corresponding integrated absorbance. Between 125 and $155 \mathrm{~K}$, all of the integrated absorbance profiles remain flat, indicating little change in the intensity of the respective features. Water evaporation is clearly marked by the on-set of the increased depletion in the intensity of the $\mathrm{OH}$ stretching feature of water (Figure 9, curves C) at $155 \mathrm{~K}$ on the $\mathrm{NCI}$ and PCI films, while the integrated absorbances of both monolayer (Figure 9, curves $\mathrm{A}$ ) and multilayer $\mathrm{C}=\mathrm{O}$ features (Figure 9, curves B) of the adsorbed acetic acid are found to decrease correspondingly. Furthermore, the integrated absorbance profiles of the $\mathrm{OH}$ stretching feature (Figure 9, curves C) are found to level off at $164 \mathrm{~K}$, indicating complete evaporation of the ice substrate. Correspondingly, the integrated absorbances of the monolayer $\mathrm{C}=\mathrm{O}$ features of acetic acid at 
$1695 \mathrm{~cm}^{-1}$ on NCI and PCI films (Figure 9, curves A) are both reduced to zero from 155 to $164 \mathrm{~K}$, providing evidence for water coevaporation with acetic acid in the interface region. The gradual reduction in the integrated absorbances of the multilayer $\mathrm{C}=\mathrm{O}$ features of acetic acid at $1717 \mathrm{~cm}^{-1}$ on both NCI and PCI films (Figure 9, curves B) from $155 \mathrm{~K}$ to above $164 \mathrm{~K}$ is consistent with the coevaporation picture and the continued evaporation of acetic acid after complete depletion of the ice film. Moreover, the rate of reduction of the multilayer $\mathrm{C}=\mathrm{O}$ feature at $1717 \mathrm{~cm}^{-1}$ with increasing temperature is found to be smaller than that of the monolayer $\mathrm{C}=\mathrm{O}$ feature at 1695 $\mathrm{cm}^{-1}$ (as indicated by the slopes of the corresponding profiles) above $155 \mathrm{~K}$ for both NCI and PCI films (Figure 9), suggesting that the interactions among acetic acid molecules are stronger than those between acetic acid and water (i.e. those found in the first monolayer). During the thermal evolution, the integrated absorbance of the $\mathrm{OH}$ dangling-bond feature of water at 3696 $\mathrm{cm}^{-1}$ (Figure 9, curves D) remains unchanged for both NCI and PCI samples, indicating that the initial adsorption of acetic acid on ice has consumed all the dangling bonds and therefore no further reduction is possible upon further annealing.

We have also conducted a similar study on the thermal evolution of the corresponding FTIR-RA difference spectra for a higher exposure of acetic acid ( $>6 \mathrm{~L}$ ) deposited on NCI and PCI films at $123 \mathrm{~K}$. The as-deposited spectra (not shown) are dominated by the intense multilayer $\mathrm{C}=\mathrm{O}$ stretching features at $1732 \mathrm{~cm}^{-1}$ at $123 \mathrm{~K}$. Similar to the case of low acetic acid exposure shown in Figures 7 and 8, water coevaporation with acetic acid is again found to begin at $155 \mathrm{~K}$ and continue until complete exhaustion of the ice film at about $165 \mathrm{~K}$. Further annealing the sample above $165 \mathrm{~K}$ produces crystallization of the remaining acetic acid, as indicated by the emergence of the characteristic bulk monomer $\mathrm{C}=\mathrm{O}$ stretch feature at $1749 \mathrm{~cm}^{-1}$ and the $\mathrm{C}-\mathrm{O}$ stretch feature at $1284 \mathrm{~cm}^{-1}$. The corresponding spectral evolution with increasing temperature for both NCI and PCI samples (not shown) follows that of a solid acetic acid film above $165 \mathrm{~K}$ (similar to those shown in Figure 3e,f). During the course of thermal evolution, we did not observe conversion of the NCI substrate to the PCI substrate before complete water evaporation has occurred. This observation suggests that the interactions between acetic acid and water are sufficiently strong that the presence of acetic acid may therefore prevent the initiation of crystallization of an ultrathin NCI film $(<6 \mathrm{~nm}$ thick). For a thicker NCI film (with thickness greater than 10 $\mathrm{nm}$ ), crystallization of NCI film has been found to proceed as expected even with the adsorption of acetic acid.

\section{Concluding Remarks}

In summary, FTIR-RA spectra have been collected for pristine solid acetic acid films and acetic acid adsorbed on ultrathin films of NCI and PCI at $123 \mathrm{~K}$, and spectral evolution upon annealing the sample to $180 \mathrm{~K}$ has also been obtained in the present work. In particular, acetic acid vapor-deposited at $123 \mathrm{~K}$ is found to exist as an amorphous solid, which undergoes a phase transformation to a more structurally ordered (polycrystalline) form between 153 and $173 \mathrm{~K}$. Two prominent $\mathrm{C}=\mathrm{O}$ stretching features were observed for acetic acid adsorbed on NCI and PCI films at $123 \mathrm{~K}$, and they could be attributed to the $\mathrm{H}$-bonded species between $\mathrm{C}=\mathrm{O}$ and the $\mathrm{OH}$ dangling bond in the first monolayer $\left(1695 \mathrm{~cm}^{-1}\right)$ and to those upon the subsequent formation of multilayers $\left(1717 \mathrm{~cm}^{-1}\right)$. The evidence of multilayer formation suggests possible formation of acetic acid islands on these NCI and PCI films. For a low exposure of acetic acid on 6-nm-thick NCI and PCI films, acetic acid is found to undergo coevaporation with water likely as an acetic acid hydrate at $155 \mathrm{~K}$, which continues until the entire ice film (substrate) has been exhausted at $165 \mathrm{~K}$. Above $165 \mathrm{~K}$, the remaining acetic acid solid appears to evaporate without undergoing the aforementioned phase transformation to a more structurally ordered form, in contrast to the case of a high acetic acid exposure ( $>6 \mathrm{~L}$ ). Furthermore, coevaporation of acetic acid with water is found to proceed at a faster rate than the subsequent evaporation of acetic acid alone, which is consistent with the weaker interactions found in the H-bonded acetic acidwater complex than that in acetic acid solids.

It is of interest to compare the present FTIR-RA spectra of acetic acid on NCI and PCI with other adsorbates. In particular, in the case of the adsorption of acetone on NCI and PCI, Schaff and Roberts ${ }^{12,39}$ and Mitlin and Leung ${ }^{19}$ reported observation of two prominent $\mathrm{C}=\mathrm{O}$ stretching features at similar frequencies, 1703 and $1717 \mathrm{~cm}^{-1}$, which can be attributed to H-bonded acetone and physisorbed (multilayer) acetone, respectively. Furthermore, Schaff and Roberts ${ }^{39}$ also observed the depletion of the multilayer feature at $1717 \mathrm{~cm}^{-1}$ before the $\mathrm{H}$-bonded feature at $1703 \mathrm{~cm}^{-1}$ upon annealing acetone adsorbed on NCI to $175 \mathrm{~K}$, in marked contrast to the thermal evolution behavior of the corresponding features for acetic acid on NCI as observed in the present work. The acetone-acetone interactions are therefore weaker than acetone-water interactions. The presence of the hydroxyl group produces additional H-bonding opportunity and stronger intermolecular interactions in acetic acid. The replacement of the methyl group by the hydroxyl group as in acetic acid therefore has a significant effect on the respective chemical and physical properties of acetone and acetic acid on ice films. Furthermore, similar frequencies have also been observed for other vibrational modes for the adsorption of acetone and of acetic acid on NCI and PCI, ${ }^{39}$ further supporting the interactions between $\mathrm{C}=\mathrm{O}$ and the $\mathrm{OH}$ dangling bond as the primary adsorption mechanism for both adsorbates.

The present work provides the first infrared spectroscopic data for the adsorption of an organic acid on ice between 123 and $180 \mathrm{~K}$. Hudson et al. have investigated the uptake of acetone, acetaldehyde, and acetic acid on ice films in nearly the same temperature region $(130-180 \mathrm{~K})$ as the present study by using mass spectrometric techniques. ${ }^{20}$ Of interest to the present work is that acetic acid has also been found to be more tightly bound on ice than acetone at the lower temperature end by Hudson et al., consistent with our observation that acetic acid evaporates at a higher temperature than acetone. ${ }^{20}$ Solokov and Abbatt extended the uptake study of acetic acid (and $n$-alcohols and hexanal) on ice to $213-245 \mathrm{~K}$ and concluded among other observations that the ice surface in this temperature region behaves more like liquid than solid. ${ }^{21}$ Extension of the present spectroscopic study to this higher temperature regime would therefore be of great interest to further characterize the role of $\mathrm{H}$-bonding interactions in these adsorption studies. Not surprisingly, the adsorption behavior of small inorganic acids such as $\mathrm{HCl}$ and $\mathrm{HBr}$ on ice ${ }^{18,40,41}$ is found to be rather different from that observed in the present work. In particular, $\mathrm{HCl}$ was found to form a bound molecular state on the ice surface below $50 \mathrm{~K}$ and to penetrate into ice above $60 \mathrm{~K}$, where it subsequently dissociates as ions converting the ice to amorphous and crystalline hydrates respectively below and above $140 \mathrm{~K} \cdot{ }^{18,40}$ In addition, Hanson and Ravishankara also showed that the adsorption of $\mathrm{HBr}$ was as efficient as $\mathrm{HCl}$ on the ice surface, while HF was only weakly taken up by ice. ${ }^{41}$ In contrast, no experimental evidence for the penetration and ionization of 
acetic acid upon adsorption on NCI and PCI has been obtained under the present experimental conditions between 123 and $180 \mathrm{~K}$.

The FTIR-RA spectra of acetic acid adsorbed on the $\mathrm{Ru}(0001)$ surface at $100 \mathrm{~K}$ have been reported by Garcia et al. ${ }^{24}$ and found to be quite similar to the present data for acetic acid on NCI and PCI. With the exception of the $\mathrm{C}=\mathrm{O}$ stretching feature at $1695 \mathrm{~cm}^{-1}$ (corresponding to the acetic acid H-bonded to ice), the observed spectral similarities for the two substrates therefore indicate that the adsorption states of acetic acid on NCI and PCI could be considered as molecular and physisorbed states as those found for $\mathrm{Ru}(0001)$ at $100 \mathrm{~K} .^{24}$ The difference between metal and ice surfaces is mainly attributed to the presence of the $\mathrm{OH}$ dangling bond on the ice surface. The adsorption of acetic acid on other metal surfaces, including $\operatorname{Pt}(111),{ }^{37}$ $\mathrm{Cu}(100),{ }^{42} \mathrm{Rh}(111),{ }^{43}$ and $\mathrm{Pd}(110),{ }^{44}$ has also been reported. Like the adsorption of acetic acid on $\mathrm{Ru}(0001)$ above $100 \mathrm{~K}$, evidence of dehydrogenation and formation of acetate has been obtained for these metal surfaces at different temperatures and coverage.

Compoint et al. have studied the geometry and dynamics of acetic acid and formic acid adsorbed on/in ice by classical molecular dynamics simulation at $250 \mathrm{~K} \cdot{ }^{23}$ Unfortunately, no simulation in the temperature region employed in the present work $(123-180 \mathrm{~K})$ and that of interest to ozone depletion (190$220 \mathrm{~K}$ ) have been reported for these systems, which could provide valuable information about the structural evolution upon annealing, formation of contact ion pairs $\left(\mathrm{CH}_{3} \mathrm{COO}^{-}-\mathrm{H}_{3} \mathrm{O}^{+}\right)$, and other adsorption phenomena on ice. ${ }^{1}$ Furthermore, quantum mechanical computations of model adsorbate-ice systems have thus far been limited to small adsorbates such as $\mathrm{HCl}, \mathrm{HF}$, and $\mathrm{HBr}{ }^{45,46}$ Despite the usual limitations of these quantum computations, these calculations could provide qualitative insights into the larger oxygenated hydrocarbons (such as acetic acid). Our recent calculations on acetic acid monohydrate and dihydrate using the density functional method have provided support for the observed trends in the relative strengths of the H-bonding interactions among water, acetic acid, and their hydrates. $^{47}$ The present spectroscopic data are expected to stimulate further computational studies of larger systems to improve our understanding of the intricate phenomena of oxygenated hydrocarbons on ice and of their associated $\mathrm{H}$ bonding interactions.

Acknowledgment. This work was supported by the Natural Sciences and Engineering Research Council of Canada.

\section{References and Notes}

(1) Girardet, C.; Toubin, C. Surf. Sci. Rep. 2001, 44, 159.

(2) Sanford, S. A. Polarimetry of the interstellar medium. Astron. Soc. Pac. Conf. Series 1996, 97, 29.

(3) Solomon, S. Rev. Geophys. 1988, 26, 131.
(4) Fan, S. M.; Jacob, D. J. Nature 1992, 359, 522.

(5) Finlayson-Pitts, B. J.; Livingston, F. E.; Berko, H. N. Nature 1990 343,622 .

(6) Brasseur, G.; Granier, C. Science 1992, 257, 1239.

(7) Hofmann, D. J.; Solomon, S. J. J. Geophys. Res. 1989, 94, 5029.

(8) Zellner, R. Global Aspects of Atmospheric Chemistry; Springer: New York, 1999.

(9) Seinfeld, J. H.; Pandis, S. N. Atmospheric Chemistry and Physics: From Air Pollution to Climate Change; Wiley: New York, 1998.

(10) Devlin, J. P. J. Phys. Chem. 1992, 96, 6185.

(11) Horn, A. B.; Chesters, M. A.; McCoustra, M. R. S.; Sodeau, J. R. J. Chem. Soc., Faraday Trans. 1992, 88, 1077.

(12) Schaff, J. E.; Roberts, J. T. J. Phys. Chem. 1994, 98, 6900

(13) Rowland, B.; Fisher, M.; Devlin, J. P. J. Chem. Phys. 1991, 95, 1378.

(14) Kuhs, W. F.; Lehmann, M. S. Water Sci. Rev. 1986, 2, 1.

(15) Buch, V.; Devlin, J. P. J. Chem. Phys. 1991, 94, 4091.

(16) Rowland, B.; Devlin, J. P. J. Chem. Phys. 1991, 94, 812

(17) Andrews, L.; Arlinghaus, R. T.; Johnson, G. L. J. Chem. Phys. 1983, 78,6347 .

(18) Delzeit, L.; Rowland, B.; Devlin, J. P. J. Phys. Chem. 1993, 97 10312 .

(19) Mitlin, S.; Leung, K. T. Surf. Sci. 2002, 505, L227.

(20) Hudson, P. K.; Zondlo, M. A.; Tolbert, M. A. EOS, Transactions 1999, 80, S75.

(21) Sokolov, O.; Abbatt, J. P. D. J. Phys. Chem. A 2002, 106, 775.

(22) Guerinot, G. Ph.D. Thesis, Université Joseph Fourier, Grenoble, France, 2000.

(23) Compoint, M.; Toubin, C.; Picaud, S.; Hoang, P. N. M.; Girardet, C. Chem. Phys. Lett. 2002, 365, 1.

(24) Garcia, A. R.; da Silva, J. L.; Ilharco, L. M. Surf. Sci. 1998, 415, 183.

(25) Mitlin, S.; Leung, K. T. J. Phys. Chem. B 2002, 106, 6234.

(26) Whalley, E. Can. J. Chem. 1977, 55, 3429.

(27) Ataka, K.; Yotsuyanagi, T.; Osawa, M. J. Phys. Chem. 1996, 100, 10664

(28) Bertie, J. E.; Labbe, H. J.; Whalley, E. J. Chem. Phys. 1969, 50, 4501.

(29) Mitlin, S.; Leung, K. T. Can. J. Chem. 2004, 82, 978.

(30) Bertagnolli, H. Chem. Phys. Lett. 1982, 93, 287.

(31) Bellamy, L. J.; Lake, R. F.; Pace, R. J. Spectrochim. Acta 1963, 19,443 .

(32) Haurie, M.; Novak, A. J. Chim. Phys. 1965, 62, 137.

(33) Krause, P. F.; Katon, J. E.; Rogers, J. M.; Phillips, D. B. Appl. Spectrosc. 1977, 31, 110 .

(34) Haurie, M.; Novak, A. J. Chim. Phys. 1965, 62, 146.

(35) Haurie, M.; Novak, A. Spectrochim. Acta 1965, 21, 1217.

(36) Berney, C. V.; Redington, R. L.; Lin, K. C. J. Chem. Phys. 1970, 53,1713 .

(37) Gao, Q.; Hemminger, J. C. J. Electron Spectrosc. Related Phenom. 1990, 54/55, 667

(38) Yokoyama, I.; Miwa, Y.; Machida, K. Bull. Chem. Soc. Jpn. 1992, $65,746$.

(39) Schaff, J. E.; Roberts, J. T. Langmuir 1998, 14, 1478.

(40) Delzeit, L.; Rowland, B.; Devlin, J. P. J. Phys. Chem. 1993, 97, 10312

(41) Hanson, D. R.; Ravishankara, A. R. J. Phys. Chem. 1992, 96, 9441

(42) Sexton, B. A. Chem. Phys. Lett. 1979, 65, 3, 469

(43) Hoogers, G.; Papageorgopoulos, D. C.; Ge, Q.; King, D. A. Surf. Sci. 1995, 340, 23.

(44) Aas, N.; Bowker, M. J. Chem. Soc., Faraday Trans. 1993, 89, 1249.

(45) Calatayud, M.; Courmier, D.; Minot, C. Chem. Phys. Lett. 2003, 369, 287.

(46) Al-Halabi, A.; Bianco, R.; Hynes, J. T. J. Phys. Chem. A 2002, 106, 7639.

(47) Gao, Q.; Leung, K. T. J. Chem. Phys. 2005, in press 